\title{
Out of the dark: transitional subsurface-to-surface microbial diversity in a terrestrial serpentinizing seep (Manleluag, Pangasinan, the Philippines)
}

\section{Kristin M. Woycheese ${ }^{1 *}$, D'Arcy R. Meyer-Dombard $^{1}$, Dawn Cardace $^{2}$, Anacleto M. Argayosa ${ }^{3}$ and Carlo A. Arcilla ${ }^{4}$}

${ }^{1}$ Department of Earth and Environmental Sciences, University of Illinois at Chicago, Chicago, IL, USA

${ }^{2}$ Department of Geosciences, University of Rhode Island, Kingston, RI, USA

${ }^{3}$ Institute of Biology, University of the Philippines Diliman, Quezon City, Philippines

${ }^{4}$ National Institute of Geological Sciences, University of the Philippines Diliman, Quezon City, Philippines

\section{Edited by:}

John R. Spear, Colorado School of Mines, USA

\section{Reviewed by:}

Matthew Schrenk, Michigan State

University, USA

Tim Magnuson, Idaho State

University, USA

\section{*Correspondence:}

Kristin M. Woycheese, Department of Earth and Environmental Sciences, University of Illinois at Chicago, 845 W. Taylor St., M/C 186, Chicago, IL 60607, USA

e-mail: kwoych2@uic.edu
In the Zambales ophiolite range, terrestrial serpentinizing fluid seeps host diverse microbial assemblages. The fluids fall within the profile of $\mathrm{Ca}^{2+}-\mathrm{OH}^{-}$-type waters, indicative of active serpentinization, and are low in dissolved inorganic carbon (DIC) $(<0.5 \mathrm{ppm})$. Influx of atmospheric carbon dioxide $\left(\mathrm{CO}_{2}\right)$ affects the solubility of calcium carbonate as distance from the source increases, triggering the formation of meter-scale travertine terraces. Samples were collected at the source and along the outflow channel to determine subsurface microbial community response to surface exposure. DNA was extracted and submitted for high-throughput 16S rRNA gene sequencing on the Illumina MiSeq platform. Taxonomic assignment of the sequence data indicates that $8.1 \%$ of the total sequence reads at the source of the seep affiliate with the genus Methanobacterium. Other major classes detected at the source include anaerobic taxa such as Bacteroidetes (40.7\% of total sequence reads) and Firmicutes $(19.1 \%$ of total reads). Hydrogenophaga spp. increase in relative abundance as redox potential increases. At the carbonate terrace, $45 \%$ of sequence reads affiliate with Meiothermus spp. Taxonomic observations and geochemical data suggest that several putative metabolisms may be favorable, including hydrogen oxidation, $\mathrm{H}_{2}$-associated sulfur cycling, methanogenesis, methanotrophy, nitrogen fixation, ammonia oxidation, denitrification, nitrate respiration, methylotrophy, carbon monoxide respiration, and ferrous iron oxidation, based on capabilities of nearest known neighbors. Scanning electron microscopy and energy dispersive $\mathrm{X}$-ray spectroscopy suggest that microbial activity produces chemical and physical traces in the precipitated carbonates forming downstream of the seep's source. These data provide context for future serpentinizing seep ecosystem studies, particularly with regards to tropical biomes.

Keywords: serpentinization, Zambales, deep subsurface biosphere, Illumina 16S rRNA, carbonate precipitation, hydrogen oxidation

\section{INTRODUCTION}

Deep subsurface habitats are critical to the evolution and sustainability of life on Earth. These habitats have potentially served as refugia from mass extinction events numerous times throughout Earth's history. Multiple examples of hydrothermal systems supporting the chemolithotrophic growth of thermophilic and hyperthermophilic archaea have been documented from the subseafloor (Amend and Teske, 2005). Studies of microbial community dynamics in subseafloor sediments suggest that symbiotic relationships occur between sulfate reducing bacteria and ammonia-oxidizing archaea in the Miscellaneous Crenarchaeotal Group (MCG) (Amend and Teske, 2005). The oligotrophic nature of these environments likely fuels such symbioses out of necessity.

The deep terrestrial subsurface is also proposed to support a vast biosphere, where total cell counts range from $3.5 \times 10^{30}$ to
$2.9 \times 10^{20}$ (Whitman et al., 1998; Kallmeyer et al., 2012). The release of hydrogen gas $\left(\mathrm{H}_{2}\right)$ from diverse geologic processes may support a vast $\mathrm{H}_{2}$-based deep subsurface biosphere (Nealson et al., 2005). Serpentinization (i.e., the low-temperature hydrous alteration of olivine and pyroxene) is known to produce volumes of $\mathrm{H}_{2(\mathrm{~g})}$ and $\mathrm{CH}_{4(\mathrm{~g})}$ (Cardace and Hoehler, 2009; Marlow et al., 2014) via the following reactions:

$$
\begin{aligned}
(\mathrm{Fe}, \mathrm{Mg})_{2} \mathrm{SiO}_{4}+ & \mathrm{H}_{2} \mathrm{O}_{(\mathrm{l})} \rightarrow(\mathrm{Fe}, \mathrm{Mg})_{3} \mathrm{Si}_{2} \mathrm{O}_{5}(\mathrm{OH})_{4} \\
& +(\mathrm{Mg}, \mathrm{Fe})(\mathrm{OH})_{2}+\mathrm{Fe}_{3} \mathrm{O}_{4}+\mathrm{H}_{2(\mathrm{~g})} \\
4 \mathrm{H}_{2(\mathrm{~g})}+\mathrm{CO}_{2(\mathrm{~g})} \rightarrow & \mathrm{CH}_{4}(\mathrm{~g})+2 \mathrm{H}_{2} \mathrm{O}_{(\mathrm{l})}
\end{aligned}
$$

The highly exothermic serpentinization reaction (Equation 1) proceeds as olivine becomes hydrated by meteoric water to 
produce serpentine, brucite, magnetite, and hydrogen gas. Methane production becomes thermodynamically favorable under these circumstances (Equation 2), and may be catalyzed abiotically (i.e., Fischer-Tropsch Type, or FTT, synthesis) or via biological methanogenesis (Schrenk et al., 2013). Isolated from the atmospheric reservoir, carbon dioxide $\left(\mathrm{CO}_{2}\right)$ becomes limited in the deep subsurface system. Exposure to atmospheric $\mathrm{CO}_{2}$ at the terrestrial surface results in precipitation of calcium carbonate $\left(\mathrm{CaCO}_{3}\right)$ from the alkaline, calcium-rich fluid:

$$
\mathrm{Ca}^{+2}+\mathrm{CO}_{3}^{-2} \rightarrow \mathrm{CaCO}_{3}
$$

As precipitation occurs along the outflow channel, $\mathrm{CaCO}_{3}$ crystals may entomb biological material and geochemically preserve microbial activity. Analysis of carbonates associated with serpentinizing seeps may therefore provide insight for the interpretation of analogous fossil systems on Earth (Blank et al., 2009).

The purpose of this study is to characterize the microbial community along the outflow channel of a terrestrial serpentinizing seep via high-throughput $16 \mathrm{~S}$ rRNA gene amplicon sequencing analysis, and determine the effects of surface exposure on microbial diversity. Manleluag Spring National Park is located in the Pangasinan province, the Philippines. The park hosts several known serpentinizing seeps originating in a weathering ophiolite range in a densely vegetated, tropical biome. Uranium-thorium radiometric dating suggests that the Zambales ophiolite complex is approximately $40 \mathrm{Myr}$ old, placing formation of the oceanic crust in a nascent island arc during Eocene seafloor spreading (Hawkins and Evans, 1983; Abrajano et al., 1988). Average $\delta \mathrm{D}_{\mathrm{CH} 4}$ values of $-136 \%$ suggest thermogenic production of $\mathrm{CH}_{4}$ at temperatures $\sim 110-125^{\circ} \mathrm{C}$, consistent with active serpentinization (Abrajano et al., 1988). Previous work at Los Fuegos Eternos (approximately $50 \mathrm{~km}$ southwest of Manleluag) suggests that serpentinization in Zambales produces an average ratio of 55:42 $\mathrm{CH}_{4}: \mathrm{H}_{2}$ (Abrajano et al., 1988). In general, previous work has suggested that methane and molecular hydrogen in Zambales gas seeps is originating from the serpentinization reaction involving ultramafic rock and meteoric (not mantle-derived) water (Abrajano et al., 1988, 1990).

There are numerous publications to date investigating the geobiology of ultramafic systems (Barnes et al., 1978; Blank et al., 2009; Etiope et al., 2011; Brazelton et al., 2013; Cardace et al., 2013; Suzuki et al., 2013; Szponar et al., 2013; SánchezMurillo et al., 2014; Meyer-Dombard et al., 2015). However, tropical serpentinizing seeps are relatively scarce in the literature (Schrenk et al., 2013; Sánchez-Murillo et al., 2014). Tropical systems are of particular interest to serpentine-hosted microbial community analysis given the potential for relatively higher influxes of dissolved inorganic and organic carbon via meteoric water input (Abrajano et al., 1990). Investigations of terrestrial serpentinizing seep fluid communities may also have broader interest to Early Earth and astrobiology studies. Oceanic mafic and ultramafic rocks were widespread on Early Earth, and ophiolite terranes have been suggested as particularly compelling analogs for astrobiology studies (Blank et al., 2009). These findings may therefore provide clues to life's earliest origins (Russell, 2003).

\section{MATERIALS AND METHODS GEOCHEMISTRY}

Fluid and solid samples were collected concurrently with samples for DNA analysis to characterize the geochemical environment of the microbial community. Briefly, fluids were collected via peristaltic pump through Sterivex ${ }^{\mathrm{TM}}$ filter units (EMD Millipore, Merck KGaA, Darmstadt, Germany) for DIC, DOC, cation/anion, and $\mathrm{C}$ and $\mathrm{N}$ isotope analysis. Solid material was collected for $\mathrm{C}$ and $\mathrm{N}$ isotope analysis, freeze dried, and sent to the University of Arizona for analysis by EA-irMS. Dissolved gas was collected in acid-washed, $10 \mathrm{~mL}$ glass serum vials sealed with butyl stoppers and flushed with argon gas. Approximately $5 \mathrm{~mL}$ of sample fluid was added to the vial, and the gas in the headspace analyzed via gas chromatography (Varian Saturn ${ }^{\circledR} 2200$ GCMS/MS, Agilent Technologies, Santa Clara, CA, USA) at the University of Chicago. For a detailed explanation of fluid, solid, and gas geochemistry protocols referred to in this manuscript, please see Cardace et al. (2015), and Meyer-Dombard et al. (2015).

\section{FIELD SITE}

The field site is located at Manleluag Spring National Park $\left(\mathrm{N} 15^{\circ} 42^{\prime} 16^{\prime \prime} \mathrm{E} 120^{\circ} 16^{\prime} 52^{\prime \prime}\right)$ in Mangatarem, Pangasinan province, the Philippines, approximately $270 \mathrm{~km}$ northwest of Manila. The site is part of the Acoje block of the middle ultramafic belt of the Zambales ophiolite range (Abrajano et al., 1990). The climate is tropical, with average annual temperatures of $27.4^{\circ} \mathrm{C}$, and average annual rainfall of $2223 \mathrm{~mm}$. For a detailed analysis of the aqueous geochemistry and bioenergetics of the system, please see Cardace et al. (2015).

Samples were collected in 2012 and 2013 along the outflow channel of a serpentinizing seep named Manleluag 2 (ML2) (Figure 1). Fluid and solid samples for molecular microbial community analysis, microscopy, and geochemistry were collected at three locations: (1) the source pool (ML2U); (2) in a larger, meter-wide pool below the source (ML2L); and (3) at carbonate terraces approximately 10 meters downstream (CC1). Solid samples and meter readings were collected from a fourth location (CC2) (Figure 1). CC1 and CC2 are subsets of the location described as "ML3" in Cardace et al. (2015). Samples for DNA extraction were collected at ML2U, ML2L, and CC1 for highthroughput sequence analysis.

\section{SEM-EDX}

A Hitachi S-3000N Variable Pressure Scanning Electron Microscope (SEM; Hitachi High-Technologies Corporation, Tokyo, Japan) was used to confirm the presence of microbes in solid samples. The SEM is equipped with an Oxford INCA energy dispersive X-ray spectroscopy (SEM-EDX), with a light element X-ray detector (Oxford Instruments, Tubney Woods, Abingdon, Oxfordshire, UK). Samples were freeze-dried in a Labconco Freeze Dry System/Freezone 4.5 (Labconco, Kansas City, MO, USA) and attached to aluminum stubs with carbon tape (Electron Microscopy Sciences, Hatfield, PA, USA). Samples were uncoated and unpolished. Images were acquired with the backscattered electron detector using an accelerating voltage of $10-20 \mathrm{kV}$ in variable pressure mode (ranging from $10 \mathrm{~Pa}$ to $70 \mathrm{~Pa}$ pressure). Weight percent of elements were 


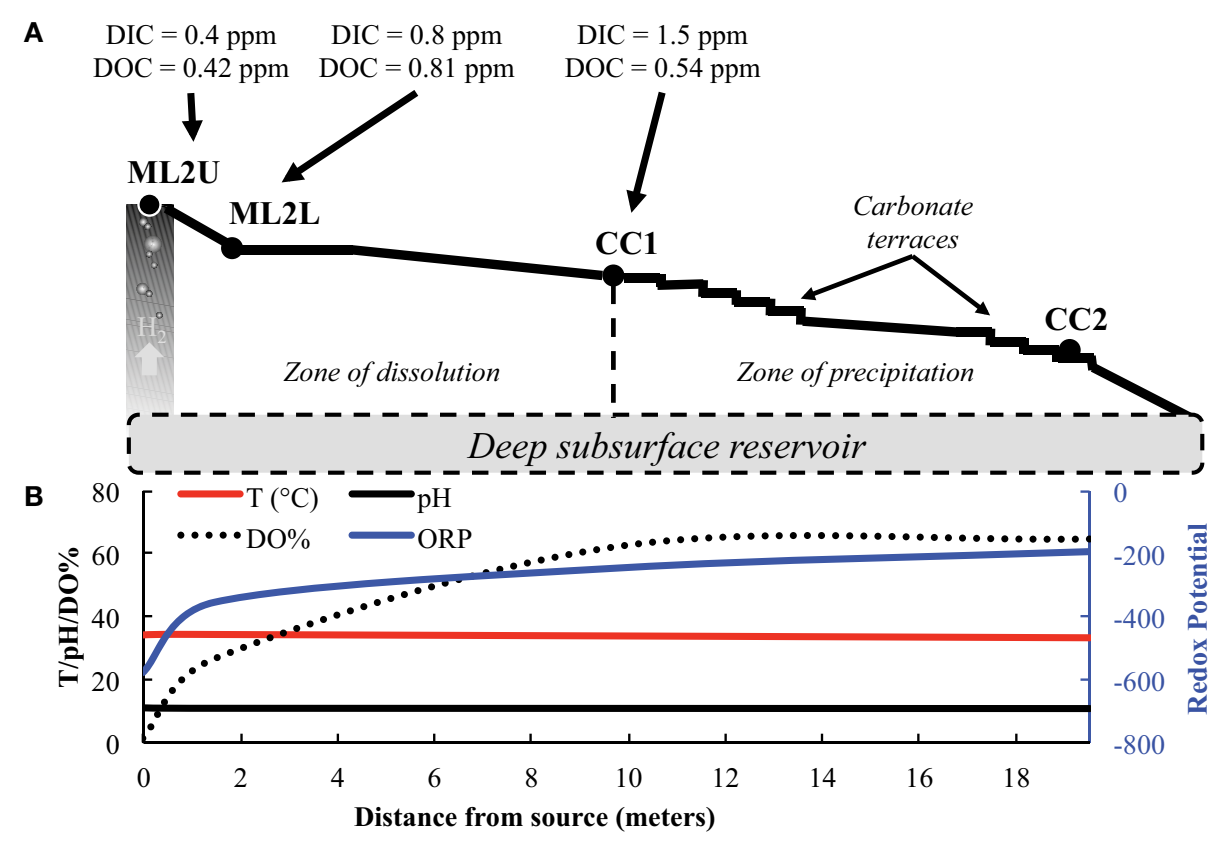

FIGURE 1 | Manleluag source and outflow channel site sampling regime. (A) Samples were collected from Manleluag Seep 2 Upper (ML2U), Lower (ML2L), and Caustic Cascade 1 (CC1). $\mathrm{H}_{2}$ degasses from the serpentinizing fluid as it approaches ML2U. Carbon dioxide in the atmosphere dissolves as inorganic carbon (DIC) along the outflow channel. Leaf litter and insects, etc... contribute to dissolved organic carbon (DOC) along the outflow channel. Scale bar denotes distance from source in meters. (B) Selected geochemical data from Manleluag; temperature, $\mathrm{pH}$, and DO\% are presented on the primary $y$-axis, ORP (oxidative-reductive potential) on the secondary $y$-axis, and distance from the source, in meters, on the x-axis. Please see Cardace et al. (2015), for a detailed analysis of geochemical parameters. measured with the X-ray detector at a standard working distance of $15 \mathrm{~mm}$.

\section{DESCRIPTION OF CARBONATES}

The following terminology is used here to describe the travertine carbonate deposits at Manleluag: terrace refers to meter-scale structures which form as water pools in the dam created by precipitating carbonate; rimstone dam refers to the exposed rim of the terrace; terracettes refer to cm-scale features, and microterracettes to mm-scale features on faces of rimstone dams.

Calcium carbonate solubility was calculated via fluid chemistry data from ML2U, ML2L, and CC1. Carbonate speciation was adjusted for the $\mathrm{pH}$ at each site, but calculations were otherwise performed at standard temperature and pressure. The total dissolved inorganic carbon (DIC) represents the total carbon in the system $\left(\mathrm{C}_{\mathrm{T}}\right)$. See the Supplemental Material for a complete account of equations.

\section{DNA EXTRACTION}

Samples for DNA analysis were collected in sterile Whirl-Pak bags (Nasco, Fort Atkinson, WI, USA) and transported on ice. Samples were stored in $\mathrm{a}-20^{\circ} \mathrm{C}$ freezer until processing. Environmental DNA was extracted with the PowerBiofilm ${ }^{\mathrm{TM}}$ DNA Isolation Kit (MO BIO Laboratories, Inc., Carlsbad, CA, USA) in replicate, and samples were pooled, concentrated, and purified using the QIAquick ${ }^{\circledR}$ PCR Purification Kit (QIAGEN, Germantown, MD, USA).

\section{ILLUMINA MiSeq SEQUENCING}

Samples were sequenced on the Illumina MiSeq platform (Illumina, Inc., San Diego, CA, USA) at Argonne National Laboratory's Institute for Genomics and Systems Biology Next Generation Sequencing Core (IGSB-NGS) (Argonne, IL, USA). Region-specific primers were used to amplify the V4 region (515F-806R) of the 16S rRNA (rDNA) gene. These primers are optimized to be nearly universal across bacterial and archaeal domains, but provide poor coverage of eukaryal sequences (Walters et al., 2011). Paired-end reads were analyzed using the QIIME pipeline (Caporaso et al., 2010a). Briefly, sequences were demultiplexed, barcode-trimmed, and quality filtered. Operational taxonomic units (OTUs) were selected with a 97\% identity threshold using the UCLUST algorithm (Edgar, 2010). Representative sets of sequences were selected for taxonomy assignment using the RDP classifier (Wang et al., 2007; McDonald et al., 2012; Werner et al., 2012). Sequences were aligned with PyNAST against the Greengenes core set default reference alignment (DeSantis et al., 2006; Caporaso et al., 2010b). The aligned sequences were filtered for gaps and non-conserved positions, and the filtered alignment used to produce phylogenetic trees using the FastTree 2.1.3 algorithm in QIIME (Price et al., 2010). Rarefaction of sequence data was conducted to calculate alpha and beta diversity. Faith's phylogenetic diversity, Chao1, and observed species counts were calculated for each sample. Weighted and unweighted UPGMA diversity distance matrices were also calculated for each sample, and a consensus 
hierarchical dendrogram was constructed (Lozupone and Knight, 2005; Vazquez-Baeza et al., 2013).

\section{NUCLEOTIDE SEQUENCE ACCESSION NUMBER}

Nucleotide sequence data have been submitted to the NCBI SRA database under project accession number PRJNA269301.

\section{RESULTS}

\section{SITE DESCRIPTION}

The serpentinizing seep is located on a densely vegetated slope in the eastern Zambales Mountains (Figure 2A). The seep's surface expression creates a small, deep pool in the gabbro bedrock (Figure 2B). The outflow cascades over the bedrock and forms a wide, shallow pool (Figure 2B). Approximately 10 meters along the outflow channel, precipitation of calcium carbonate creates meters of cascading terraces (Figures 2C,D, 3). Temperature and $\mathrm{pH}$ decrease slightly from the source pool at ML2U to the carbonate terraces at CC2 (Table 1). The oxidation-reduction potential (ORP) is lowest at the source, and becomes more positive with distance from the source (Table $\mathbf{1}$ ).

The concentration of DIC increases three-fold from the source to the terraces (Table 1). Additional organic input enters the stream in the form of soil, vegetation, and insects (Figure 1) and DIC fluctuates along the outflow channel (Table 1). Weight percent of carbon in solids decreases initially from a value of $0.72 \mathrm{wt} . \%$, and then increases to $11.5 \mathrm{wt}$.\% (Table 1). The isotopic composition of carbon (as DIC) is increasingly depleted as distance from the source increases. In solids, isotopic composition of carbon (total, $\mathrm{C}_{\mathrm{T}}$ ), is enriched with distance from the source. The isotopic composition of DOC is relatively constant in the stream. At the source of the seep, the isotopic composition of the $\mathrm{C}_{\mathrm{T}}$ in solids and that in the DOC are equally depleted (Table $\mathbf{1}$ ).

\section{CARBONATE SOLUBILITY}

Carbonate solubility was calculated for fluids at the source (ML2U), and downstream sample sites (ML2L and CC1) based on DIC field measurements (Table 1, Figure 4). The solubility product constant $\left(\mathrm{K}_{\mathrm{sp}}\right)$ increases as distance from the source increases. Calculated values for $\mathrm{CO}_{3}^{-2}$ and $\mathrm{HCO}_{3}^{-}$in fluids increase with distance from the source. Measured values for $\mathrm{Ca}^{+2}$ increase initially, then decrease with distance from source (Figure 4). The stability field of $\mathrm{CaCO}_{3}$ shifts by an order of magnitude as $\mathrm{CO}_{3}^{-2}$ ion availability increases in the system via atmospheric exposure (Figure 5).

\section{SEM-EDX}

Plant roots and microbial filaments are confirmed in the carbonate samples collected from Manleluag (Figure 6). Elemental analysis of solids at CC2 indicates that the weight percent (wt.\%) of carbon varies between calcium-rich ( $c a, 38.2 \mathrm{wt} . \% \mathrm{C})$ and organic-rich (org, $36.16 \mathrm{wt}$ \% $\mathrm{C}$ ) bands in a cross section of a carbonate encrustation collected from a small root in the outflow channel (Table 2, Figure 7).

Sediment collected at the source seep contains iron- and titanium-rich minerals, (Table 2) and exhibits less carbonate than sites farther downstream. Crystallization of calcium carbonate is variable based on depositional environment; a lithified pool bottom (Figure 8A) shows secondary aragonitic precipitation and reworking of crystals, while the rhombohedral crystals on the terrace rim (Figure 8B) are much larger and appear less degraded/weathered.

Solids at all sites demonstrate low elemental wt.\% magnesium (Table 2). Sulfur was only detected in the organic-rich layers of

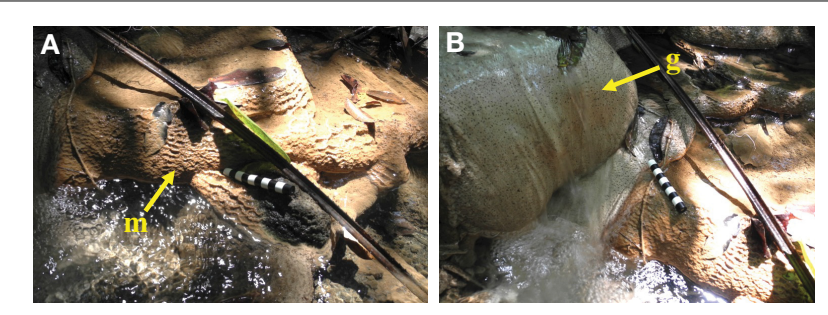

FIGURE 3 | Terrace formation at CC1. (A) Terraces range in scale from $\mathrm{mm}$ (microterracette, $m$ ) to meters. Microterracettes form evenly spaced ridges along the rims of the larger, $\mathrm{cm}$-sized terracettes. Scale bar equals $10 \mathrm{~cm}$. (B) Serpentinizing fluid flowing over gabbro forms a mound-like feature $(g)$. Scale bar equals $10 \mathrm{~cm}$.
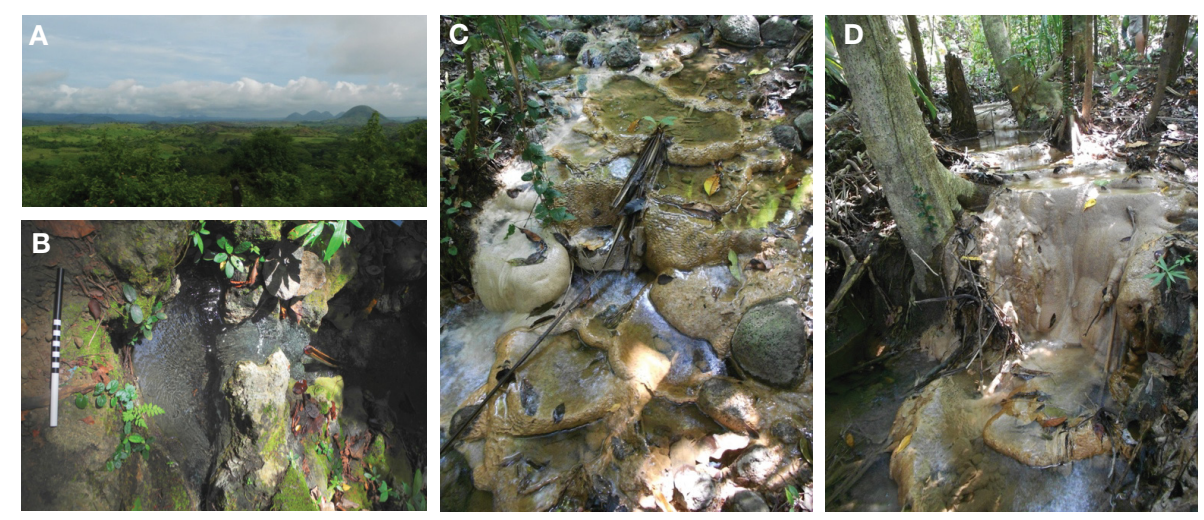

FIGURE 2 | Site location. (A) The hilly terrain of the Zambales ophiolite range in Luzon, Philippines. (B) The source seep at Manleulag Spring National Park (scale bar $=30 \mathrm{~cm}$ ). (C) Terraces and rimstone dams, $9.9 \mathrm{~m}$ from source. (D) A large accretion of terraces on tree roots and fallen branches, $19.5 \mathrm{~m}$ from source. 
Table 1 | Selected geochemical data collected from Manleluag Spring National Park.

\begin{tabular}{|c|c|c|c|c|c|c|c|c|c|c|}
\hline \multicolumn{5}{|c|}{ Site characterization } & \multicolumn{2}{|r|}{ DIC } & \multicolumn{2}{|r|}{ DOC } & \multicolumn{2}{|c|}{ Total carbon $\left(\mathrm{C}_{\mathrm{T}}\right)$ of solids } \\
\hline ML2L & 1.45 & 34.3 & 10.9 & -354.7 & 0.82 & -15.1 & 0.81 & -25.5 & 0.44 & -24.9 \\
\hline $\mathrm{CC} 1$ & 9.86 & 33.8 & 10.8 & -245.0 & 1.53 & -18.7 & 0.54 & -26.8 & 11.5 & -19.0 \\
\hline $\mathrm{CC} 2$ & 19.51 & 33.3 & 10.8 & -193.5 & $n d^{b}$ & nd & nd & nd & nd & nd \\
\hline
\end{tabular}

${ }^{a}$ VPDB, vs. Vienna Pee Dee Belemnite $\delta^{13} \mathrm{C}$ standard.

${ }^{b}$ nd, no data collected.

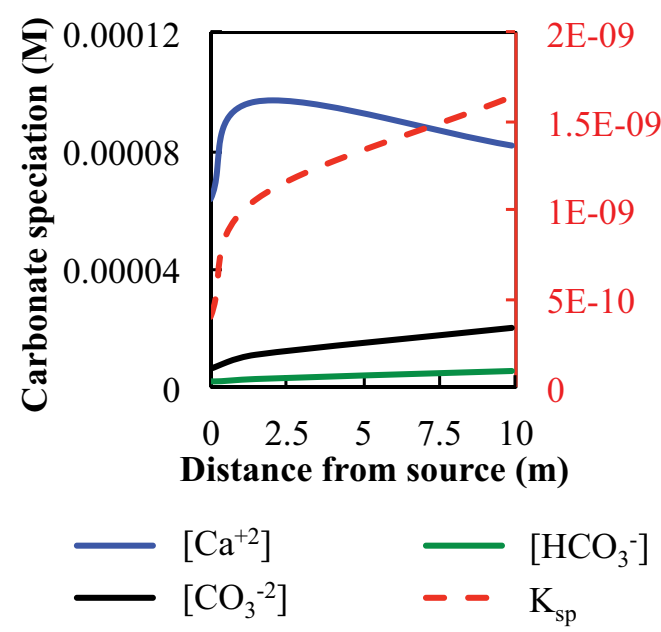

FIGURE 4 | Fluid carbonate species concentration, in $\mathrm{M}$, and calculated $\mathrm{K}_{\mathrm{sp}}$ of $\mathrm{CaCO}_{3}$ at Manleluag, plotted on a secondary axis (dashed line, red).

the encrusted root carbonate (Table 2). Titanium and manganese were only detected in source sediment. Iron, aluminum, and silica were detected in all samples, to varying degrees (Table 2). The highest elemental wt.\% iron is observed in sediment collected from the source (ML2U).

\section{S rRNA GENE AMPLICON SEQUENCING}

$16 \mathrm{~S}$ rRNA gene amplicon sequencing analysis yielded a total of 148906 reads with an average sequence length of $245.35( \pm 13.65)$. Samples were filtered to a minimum OTU count of 50, and after filtering ML2U contained 42339 sequences, ML2L contained 41419 sequences, and CC1 contained 65168 sequences.

\section{ALPHA AND BETA DIVERSITY}

Rarefaction was performed to a maximum depth of 65,000 sequences/sample and 10 replicates per iteration. Analysis of within-sample alpha diversity at Manleluag suggests that the microbial community at ML2U exhibited the highest biodiversity in all tested metrics (Supplemental Figures 1,2). A comparison of observed species and Chaol diversity indices suggests undersampling of the communities at Manleluag. UPGMA-clustered hierarchical dendrogram analysis indicates sample relatedness; ML2L and CC1 cluster more closely than ML2U (Figure 9).
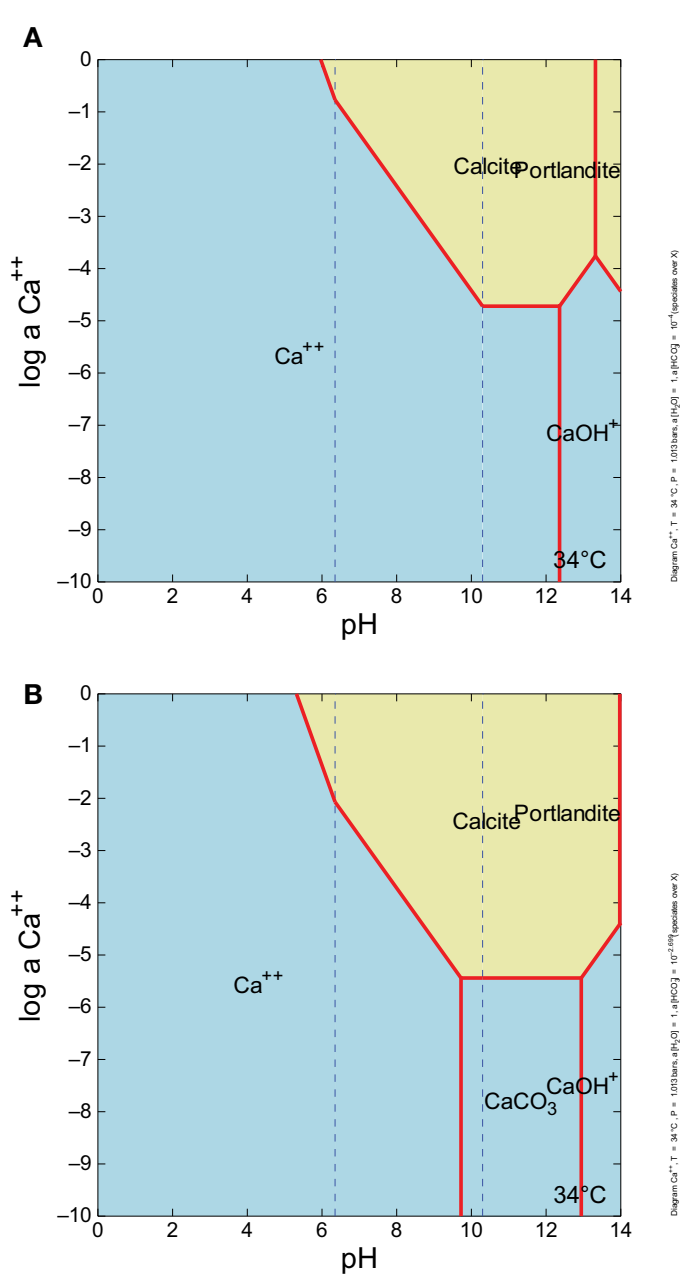

FIGURE 5 | $\mathrm{Ca}^{+2}$ activity vs. pH, with (A) $\sim 0.0001 \mathrm{~m} \mathrm{HCO}_{3}^{-}$(which is equivalent to $1 \mathrm{ppm}$ total $\mathrm{C}$ as $\mathrm{DIC}$ ), and (B) $\sim 0.002 \mathrm{~m} \mathrm{HCO}_{3}^{-}$, about what is in surface water. There is no $\mathrm{CaCO}_{3}$ aqueous complex field in the (A), but there is in (B). As $\mathrm{CO}_{2}$ increases, the aqueous $\mathrm{CaCO}_{3}$ complex field forms, and the stability field of Portlandite $\left(\mathrm{CaOH}_{2}\right)$ shifts to the right.

\section{TAXONOMY ASSIGNMENT AND OTUS}

Taxon abundance, represented as a percent of the total sequence reads, indicates that microbial community composition shifts downstream from the source as microbes adapt to an influx of oxygen, DIC, and sunlight. The most abundant taxa (OTUs 

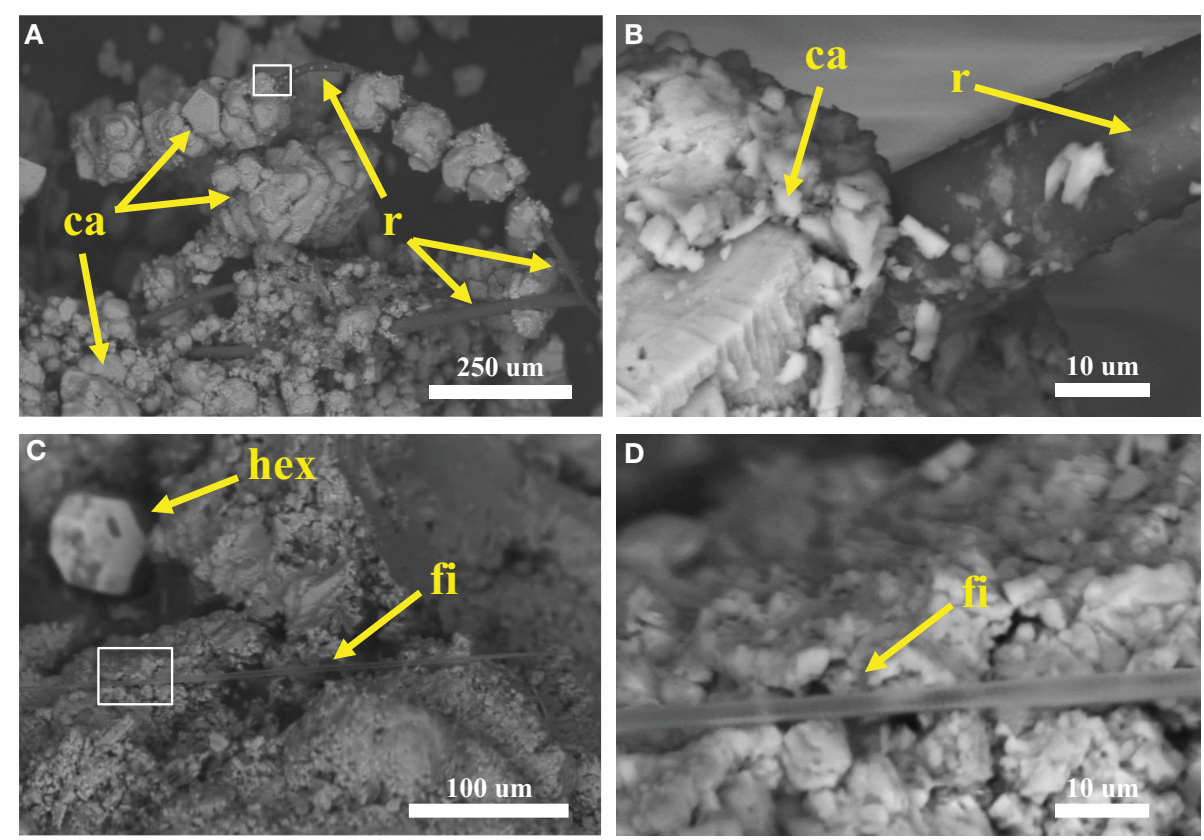

FIGURE 6 | Scanning electron microscopy (SEM) of samples collected at Manleluag Spring National Park. (A) Terrace samples consist of rhomboid calcite crystals (ca), shown here precipitating on organic matter, likely a plant

Table 2 | Elemental weight $\%$ of solids at Manleluag.

\begin{tabular}{lccccc}
\hline Wt. \% & Source sed. & Ca-rich & Org. rich & Crystal rhomb. & Root \\
\hline $\mathrm{C}$ & 24.4 & 1.72 & 36.2 & 4.86 & 52.4 \\
$\mathrm{O}$ & 32.2 & 40.9 & 41.0 & 46.5 & 30.1 \\
$\mathrm{Mg}$ & - & 2.85 & 4.4 & 2.16 & 1.2 \\
$\mathrm{Al}$ & 1.5 & 3.6 & 2.85 & 3.64 & 0.93 \\
$\mathrm{Si}$ & 2.5 & 8.88 & 7.11 & 6.65 & 2.22 \\
$\mathrm{~S}$ & - & - & 0.25 & - & - \\
$\mathrm{Ti}$ & 18.6 & - & - & - & - \\
$\mathrm{Mn}$ & 0.84 & - & - & - & - \\
$\mathrm{Ca}$ & 0.37 & 38.2 & 7.38 & 32.7 & 12.1 \\
$\mathrm{Fe}$ & 19.55 & 3.92 & 0.89 & 3.54 & 1.09 \\
\hline
\end{tabular}

that are present in the OTU table at least 50 times) varied by location. At ML2U, Methanobacterium spp. comprised $8.1 \%$ of total sequence reads (Figure 9). The most abundant taxon identified is Bacteroidetes ( $40.7 \%$ total sequence reads). Firmicutes encompass the second largest identified phyla (19.1\%). At ML2L, Proteobacteria and Thermi become increasingly abundant, and by $\mathrm{CC} 1$, Thermi, comprised almost entirely of Meiothermus spp., represents $45 \%$ of the total microbial community (Figure 9).

An OTU heatmap illustrates OTUs (phylotypes) by sample location (Figure 10). The phyla Bacteriodetes, Firmicutes, and Euryarchaeota are the most abundant taxa at ML2U. Bacteroidetes are also present in decreasing orders of abundance at ML2L and CC1 (Figure 10). Sequences related to the phylum Thermi, nearly absent at the source, increases downstream to become the most dominant phylotype at CC1 (Figure 10). root (r). (B) Close-up of box in (A). (C) Putative cyanobacterial filament ( $f$ i) interbedded with calcite crystals (note hexagonal crystal, hex, in background). (D) Close-up of box in (C).

A phylogenetic tree was constructed using the FastTree algorithm to demonstrate the relatedness between phylotypes (Supplemental Figure 3).

\section{COMPARISON TO OTHER SERPENTINIZING STUDIES}

The source microbial community was compared to taxon abundance data from other serpentinizing seep studies (Figure 11; Brazelton et al., 2010, 2013; Suzuki et al., 2013; Tiago and Veríssimo, 2013). The sediment at ML2U shares similar taxa with seep sources from other terrestrial serpentinizing seeps at the Tablelands in Newfoundland, Canada, and the Cedars, California, USA (Brazelton et al., 2013; Suzuki et al., 2013). Firmicutes and Proteobacteria were common to all seep locations, and Bacteroidetes were present in all but two (WHC2B-2010A CoDL9854 and 905GPS1) of the serpentinizing seeps (Figure 11).

\section{DISCUSSION}

Microbial community analysis via high-throughput 16S rRNA gene amplicon sequencing reveals that the deep subsurface microbial community at Manleluag responds to surface exposure with decreasing biodiversity, which is directly correlated to increased distance from the source. Meters of carbonate terraces, created by precipitation of $\mathrm{Ca}^{+2}$ from the alkaline fluids and $\mathrm{CO}_{3}^{-2}$ derived from atmospheric $\mathrm{CO}_{2}$, provide microbial habitats and record physical and geochemical evidence of microbial activity. These traits suggest that terrestrial serpentinizing ecosystems may be particularly compelling analogs for astrobiology studies.

\section{CARBONATE DISSOLUTION AND PRECIPITATION}

The precipitation and dissolution of $\mathrm{CaCO}_{3}$ is dependent on the environmental geochemical, thermodynamic, and kinetic factors 

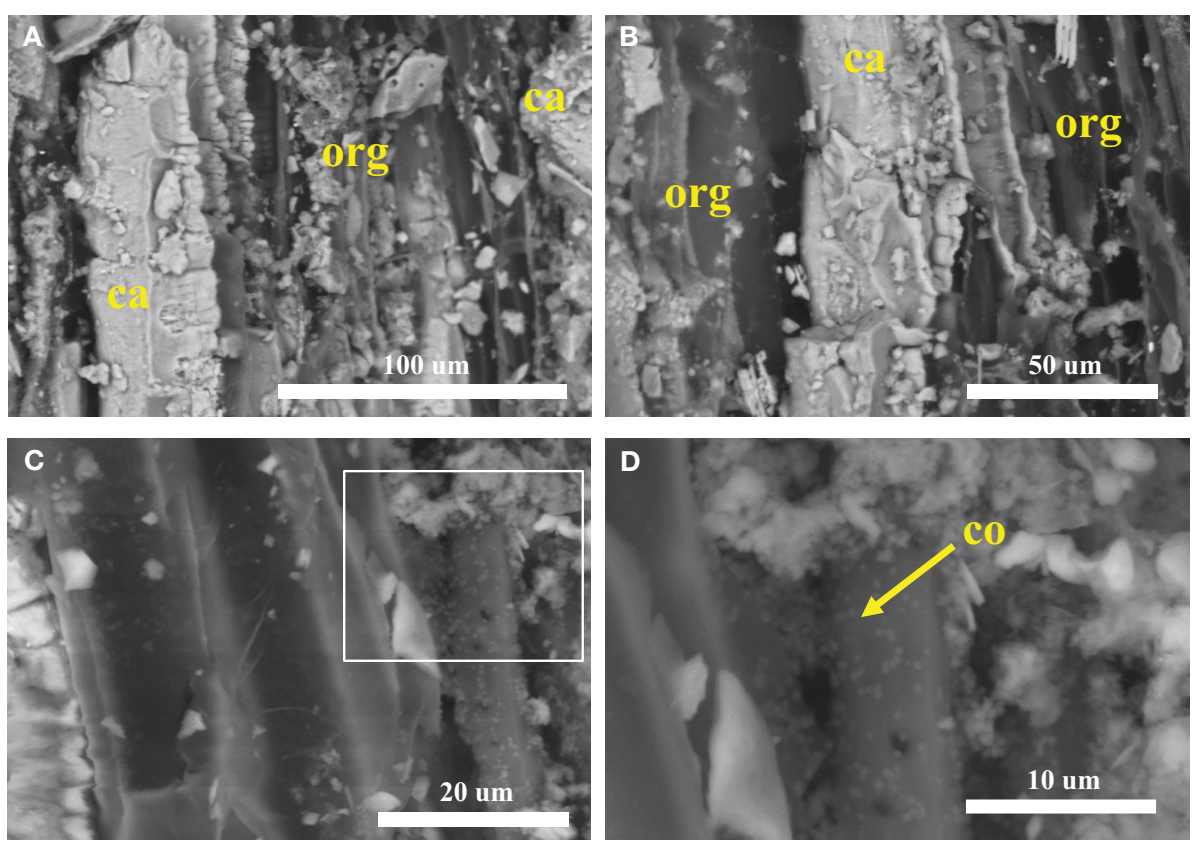

FIGURE 7 | SEM of a plant root carbonate casing, viewed in cross section. (A,B) Cross sectional view of bands of organic rich (org) and calcium-rich (ca) material. (C) Biofilm layer. (D) Close-up of box in (C) containing putative coccoid cells.
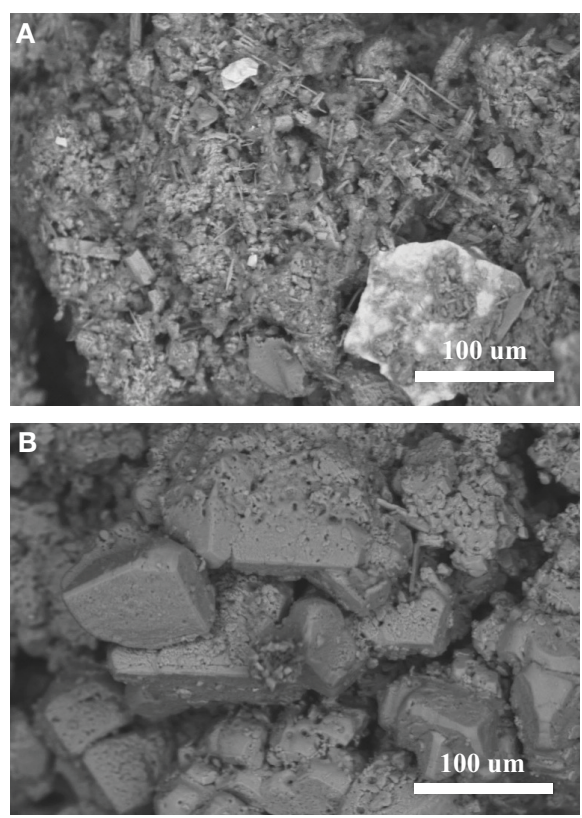

FIGURE 8 | SEM of sediments collected from Manleluag. (A) Sediment from the bottom of a pool formed by a rimstone dam at CC1. Lithified pool bottoms show evidence of secondary precipitation in the form of aragonitic needles and bushes. (B) Rhombohedral crystals from the terrace rim.

in any given system. At Manleluag, DIC increases gradually over the sampled transect, and precipitation of $\mathrm{CaCO}_{3}$ begins to occur as DIC concentrations reach $1.53 \mathrm{ppm}$ in the outflow channel. (Table 1, Figure 4). The solubility constant $\left(\mathrm{K}_{\mathrm{sp}}\right)$ of $\mathrm{CaCO}_{3}$ increases rapidly with increasing concentrations of DIC, which at $\mathrm{pH} \sim 11$ is mostly available as $\mathrm{CO}_{3}^{-2}$ (Figure 4). The elevated $\mathrm{Ca}^{+2}$ near the spring source [at about $3 \mathrm{ppm} \mathrm{Ca}^{+2}$ or $\log a \mathrm{Ca}^{+2}$ $\sim(-4.1)$; see Cardace et al., 2015] suggests that calcite precipitation is near the phase boundary between $\mathrm{Ca}^{+2}(\mathrm{aq})$ and $\mathrm{CaCO}_{3(\mathrm{~s})}$, inhibited in a sense until more bicarbonate is present (Figure 5A). At high dissolved $\mathrm{CO}_{2}$ levels, the $\mathrm{Ca}^{+2}$ is at about the same concentration, and squarely in the $\mathrm{CaCO}_{3(s)}$ field (Figure 5B).

Fine solids of $\mathrm{CaCO}_{3}$ may be forming at the source of the serpentinizing fluid, though are difficult to observe (Figure 2B). The $\mathrm{K}_{\mathrm{sp}}$ of $\mathrm{CaCO}_{3}$ (Equation 3) may increase rapidly with increasing distance from the source, given effects of partial pressure of $\mathrm{CO}_{2}$ and temperature (Morse and Arvidson, 2002). Temperature and the concentration of $\mathrm{Ca}^{+2}$ ions are relatively constant down gradient; however, precipitation becomes thermodynamically inevitable (the reaction quotient, $Q$, of serpentinizing fluids $>$ $\mathrm{K}_{\mathrm{sp}}$, for the reaction $\mathrm{CaCO}_{3} \rightarrow \mathrm{CO}_{3}^{-2}+\mathrm{Ca}^{+2}$ ), as the concentration of available $\mathrm{CO}_{3}^{-2}$ increases due to fluid equilibration with the atmosphere (Figure 4).

The isotopic composition of DIC becomes increasingly depleted as distance from the source increases, suggesting that isotopically lighter atmospheric $\mathrm{C}$ is dissolving into the fluid. In the solid sediments and biofilms collected, isotopic composition of total carbon $\left(\mathrm{C}_{\mathrm{T}}\right)$ is enriched with increasing distance from the source, while at the source the isotopic composition of $\mathrm{C}_{\mathrm{T}}$ is equally depleted as the DIC (Table 1). This may indicate that the $\mathrm{C}_{\mathrm{T}}$ of solids collected at the source originates from the DOC in the source fluid, suggesting biological assimilation in what resembles a closed-loop ecosystem (i.e., the deep subsurface). Farther downstream at site CC1, the isotopic composition of the $\mathrm{C}_{\mathrm{T}}$ in solids approaches the DIC values, again indicating that $\mathrm{CO}_{2}$ from the 


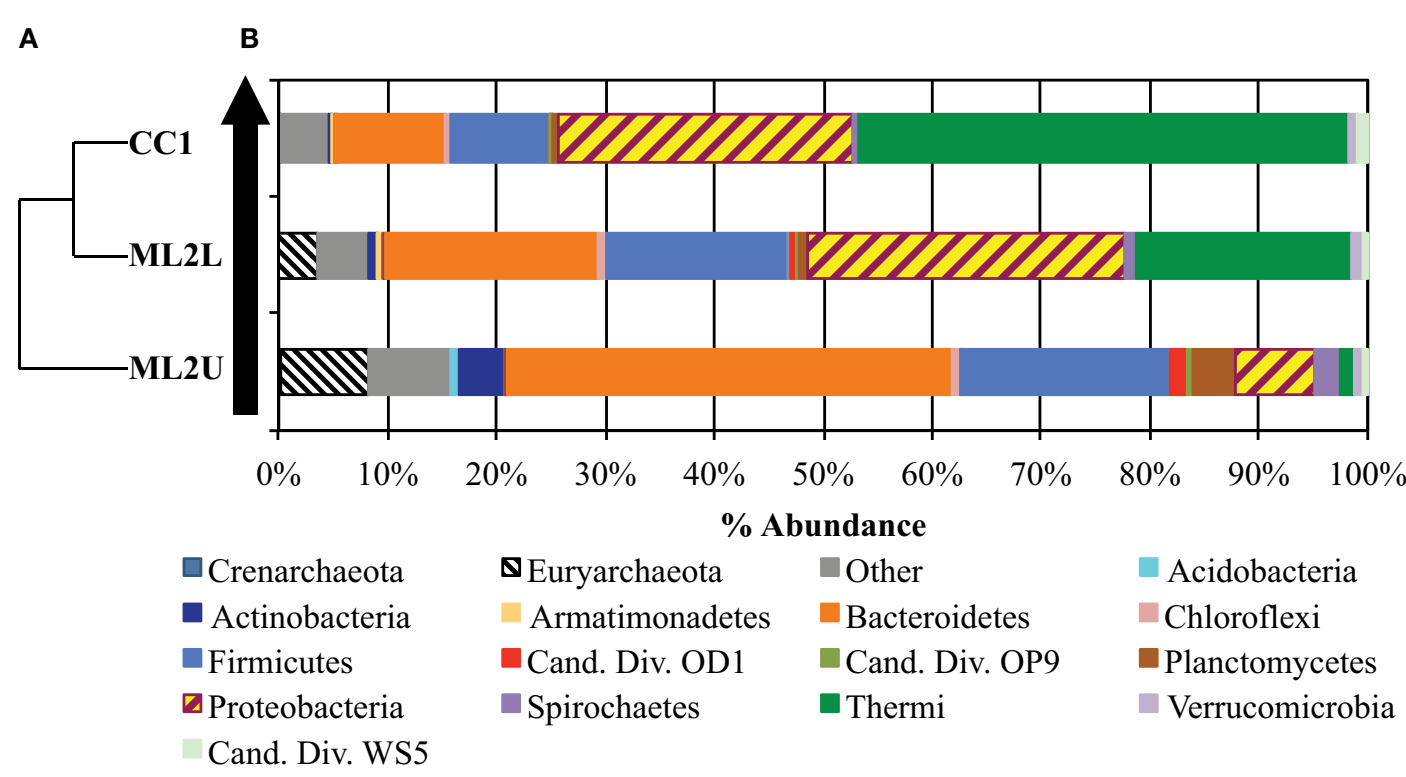

FIGURE 9 | (A) UPGMA-clustered dendrogram demonstrates relatedness between samples. (B) Histogram of OTUs present at least 50 times in the OTU table, separated by phylogenetic assignment to the Phylum level. The black arrow represents direction of flow in the seep.

\begin{tabular}{l|ccc} 
Phylum & ML2U & ML2L & CC1 \\
Euryarchaeota & 3351 & 1436 & 91 \\
Acidobacteria & 253 & 55 & 59 \\
Actinobacteria & 1042 & 134 & 75 \\
Armatimonadetes & 51 & 156 & 173 \\
Bacteria (Other) & 3111 & 1887 & 2815 \\
Bacteroidetes & 17147 & 7996 & 6454 \\
BRC1 & 79 & 57 & 21 \\
Chloroflexi & 285 & 129 & 121 \\
Firmicutes & 7817 & 6606 & 5770 \\
Nitrospirae & 35 & 95 & 14 \\
OP1 & 672 & 224 & 37 \\
OP9 & 214 & 172 & 126 \\
Planctomycetes & 132 & 1528 & 0 \\
Proteobacteria & 3202 & 11893 & 16996 \\
Spirochaetes & 259 & 890 & 0 \\
Thermi & 550 & 8123 & 29286 \\
Verrucomicrobia & 302 & 426 & 392 \\
WS5 & 221 & 132 & 656 \\
\hline
\end{tabular}

atmosphere is dissolving into the serpentinizing fluid and precipitating as $\mathrm{CaCO}_{3}$, and potentially including influence from microbial carbon fixation and heterotrophy.

\section{SEM-EDX}

SEM results (Figures 6-8) demonstrate that traces of microbial activity may be recorded in precipitated calcium carbonate triggered by serpentinizing fluid exposure to surface conditions. Carbonate-associated biofilms exhibit morphological variation based on location in the outflow channel (Figures 6-8). At CC2, the biofilms are ordered by precipitation cycles, creating bands of alternating organic-rich and mineral-rich material. EDX analysis indicates that carbon abundances vary in organic-rich layers vs. organic-poor calcium carbonate layers (Figure 7). Sulfur was only detected in the organic-rich layers, potentially suggesting sulfur cycling occurs in this layer. Given these data, it appears that at Manleluag, geochemical conditions in the serpentinizing fluid may preserve microbial chemical traces that are in part detectable with X-ray spectroscopy (Table 2, Figure 7). Further investigation via in situ isotopic measurements would be highly beneficial in ascertaining the biogenicity of these structures (Blank et al., 2009).

In general, terraces appear to preserve microbial traces more conservatively than the lithified pool bottoms, which demonstrate crystal degradation and secondary precipitation of aragonitic needles on calcite rhomboids (Figure 8). The dissolution and re-precipitation occurring in pool bottoms may re-work many physical and chemical traces of past microbial activity. These results suggest that microbial traces may be preferentially preserved in air-water interface depositional facies, such as terraces. Therefore, terraces, and not pool bottoms, may serve as more appropriate targets for analog studies.

\section{MICROBIAL TRANSMISSION FROM SUBSURFACE TO SURFACE}

The taxonomic assessment indicates that phylotypes of deep subsurface taxa continue to be present in 16S rRNA gene amplicon sequences, to the farthest extent measured (CC1). Alpha 


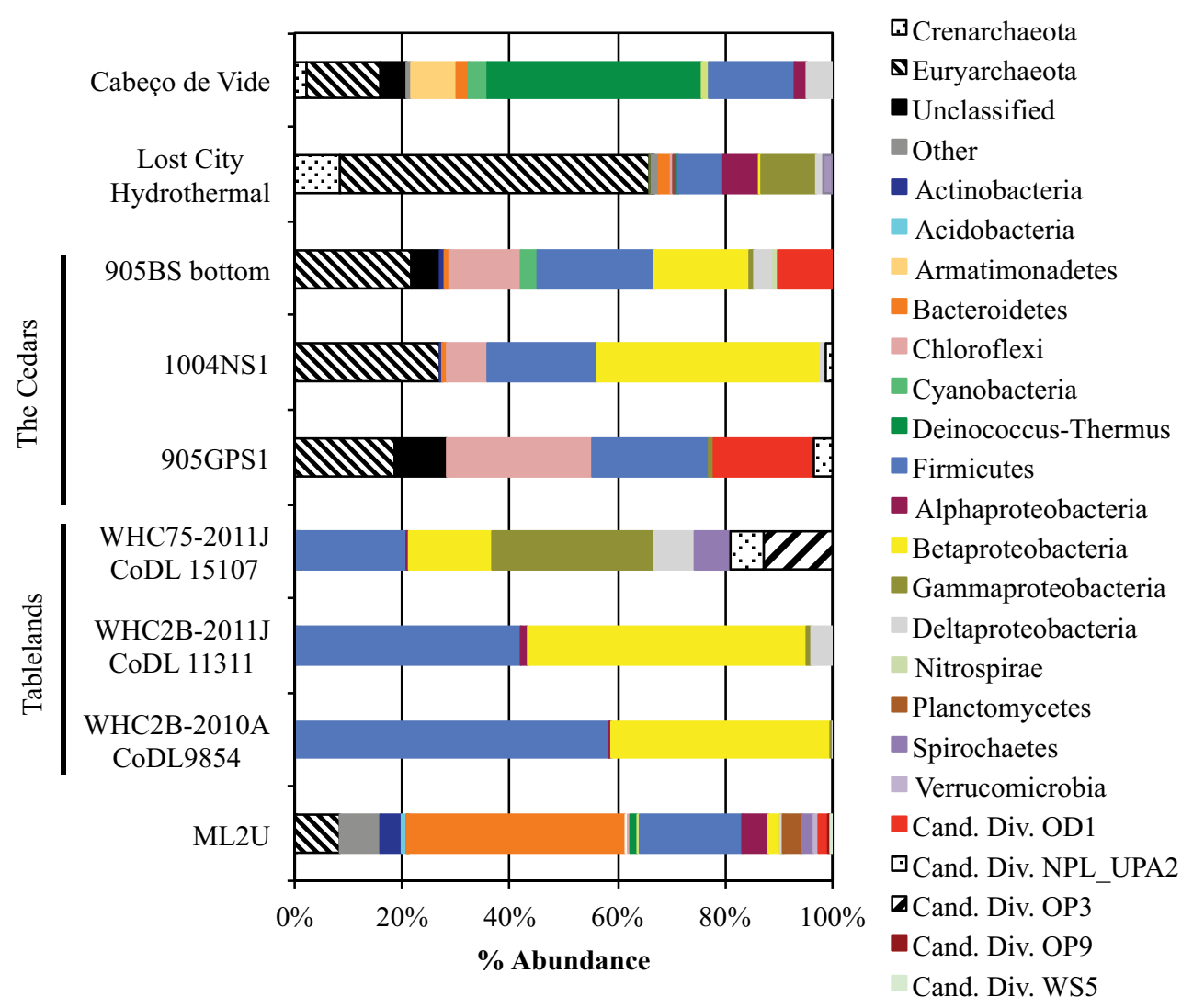

FIGURE 11 | Comparison between phylotypes from the source at Manleluag (ML2U) and results from studies of other serpentinizing systems, separated by Phylum (and class, in the Phylum

Proteobacteria). Examples include terrestrial serpentinizing seeps from Tablelands Ophiolite Complex in Newfoundland, Canada (Brazelton et al.,
2013) and the Cedars in the Coast Range Ophiolites, USA (Suzuki et al., 2013). Also included are examples from 35-year old carbonates at Lost City Hydrothermal Field (Brazelton et al., 2010) and a subterranean serpentinizing aquifer, Cabeço de Vide, in Portugal (Tiago and Veríssimo, 2013). diversity indices (measuring diversity within the sample) suggest that the source site (ML2U) is the most biodiverse; the dynamic subsurface-surface interface appears to support a wide range of facultative and obligate anaerobes and aerobes (Supplemental Figures 1,2). As an interface between the subsurface and surface environments, the pool associated with the seep orifice exemplifies an ecotone that shares characteristics of each ecosystem while also having characteristics unique to itself. Samples collected at CC1 demonstrate the least biodiversity, with nearly $45 \%$ of the sequence alignments affiliating with Meiothermus spp. This is in contrast to other terrestrial serpentinizing seep studies conducted at the Tablelands ophiolite, where TRFLP analysis suggested the highest biodiversity was found in the well-mixed freshwater end member (Brazelton et al., 2013). In Manleluag, $\mathrm{pH}$ is relatively constant $\sim 10.8$, and while dissolved oxygen becomes increasingly abundant, the concentration of bioavailable DIC remains very low. Typical of the high $\mathrm{pH}$ of serpentinizing ecosystems, $\mathrm{CO}_{3}^{-2}$ concentration is an order of magnitude higher than $\mathrm{HCO}_{3}^{-}$ in Manleluag, and this appears to suppress the diversity and abundance of photoautotrophs (Suzuki et al., 2013). The abundance of $\mathrm{CO}_{3}^{-2}$ and $\mathrm{Ca}^{+2}$ ions causes precipitation on biological surfaces (Figures 6A,B, 3). Meiothermus spp. may have some propensity for survival in this uniquely challenging environment, given its preference for alkaline environments and ability to form biofilms and anchor itself to surfaces, thus preventing being swept downstream (Kolari et al., 2003).

Sphingomonas spp., have been isolated from deep aquifers despite classification as strict aerobes (Fredrickson et al., 1999). Lautenschlager et al. (2014) demonstrated that Sphingomonas spp. are capable of oxidizing a wide range of aromatic compounds and produce acetate and methane from carbon oxidation, and calculations suggest that respiration rates are extremely low based on geochemical modeling of the environment. Similarly, this may explain the abundance of other aerobic heterotrophs at the source, such as Meiothermus spp., which may have been respiring very slowly in the deep subsurface but now thrives at the surface where oxygen is abundant (Tindall et al., 2010).

Metabolic function in Manleluag is inferred by the known metabolisms of closest neighbors of the taxa identified above, and via bioenergetics calculations based on geochemical profiling of the system (Cardace et al., 2015). These putative metabolisms may include: hydrogen oxidation, fermentation, $\mathrm{H}_{2}$-associated sulfur cycling, methanogenesis, methanotrophy, nitrogen fixation, ammonia oxidation, denitrification, nitrate 
respiration, methylotrophy, carbon monoxide respiration, and ferrous iron oxidation. The most abundant taxa identified across all three sites at Manleluag include: Sphingomonas spp., an aromatic carbon degrader (Lautenschlager et al., 2014); Meiothermus spp., an aerobic heterotroph related to Deinococcus-Thermus group taxa also detected at Lost City Hydrothermal Field and the Cabeço de Vide aquifer in Portugal (Brazelton et al., 2010; Tiago and Veríssimo, 2013); anaerobic, hydrogen oxidizing Bacteriodales (Blank et al., 2009; Tiago and Veríssimo, 2013); heterotrophic Coriobacteriaceae which align with taxa also found in the Cabeço de Vide aquifer, and may represent a surface mixing taxon (Tiago and Veríssimo, 2013); Thiobacillus spp., an obligate chemolithoautotroph known to oxidize hydrogen, reduced sulfur and ferrous iron (Kelly and Wood, 2000); Methanobacterium spp., an anaerobic methanogen typically found in deep subsurface samples and terrestrial serpentinizing seep point sources (Moser et al., 2005; Blank et al., 2009); Hydrogenophaga spp., a hydrogenoxidizer typical to serpentinizing ecosystems (Brazelton et al., 2010, 2013; Suzuki et al., 2013); Xanthomonadaceae, a carbon degrader hypothesized to belong to a deeply branching clade in the Gammaproteobacteria (Anzai et al., 2000), and Rhodobacteriaceae, chemoorganotrophs that have been detected in other serpentinizing environments (Brazelton et al., 2010; Jungbluth et al., 2014).

"Rare" taxa (less than 3\% relative abundance) include the ammonia-oxidizing archaea Thaumarchaeota, (Spang et al., 2012) and Exiguobacterium, a facultative anaerobe capable of survival in a broad range of microbial environments, detected at the source seep (Vishnivetskaya et al., 2009). Exiguobacterium sp. AB2, a haloalkaliphilic strain of Exiguobacterium, was recently isolated from samples also collected in the Manleluag seep (Cabria et al., 2014). Other rare taxa include Sporosarcina, some of which are capable of microbially induced calcite precipitation and cementation via hydrolysis of urea (Yoon et al., 2001); Alkaliphilus, an extreme alkaliphile isolated from an ultra-deep gold mine in South Africa (Takai et al., 2001); Dethiobacter, an alkaliphile that grows chemolithoautotrophically using $\mathrm{H}_{2}$ as an electron donor and thiosulfate, elemental sulfur, and polysulfide as electron acceptors (Sorokin et al., 2008); Desulfonatronum, an alkaliphilic, sulfate reducing bacterium (Pikuta et al., 2003); Mycobacterium, a ubiquitous, alkaline-tolerant genus (Bland et al., 2005); Roseococcus, an obligately aerobic, facultative alkaliphilic photoheterotroph (Boldareva et al., 2009); Roseomonas, representatives of which exhibit alkalitolerance and thermotolerance (Dong et al., 2014); Ramlibacter, a deeply branching clade isolated from weathered pyroxene, chromite and secondary calcite crystals of a meteorite collected in 1931 in Tunisia (Heulin et al., 2003); and Deinococcus, a bacterial genus known for its resistance to dessication, UV and ionizing radiation (Makarova et al., 2001).

\section{COMPARISON TO OTHER SITES}

The source seep at Manleluag (ML2U) exhibited shared phylotypes with several terrestrial, sub-seafloor, and deep aquifer serpentinizing ecosystems (Brazelton et al., 2010, 2013; Suzuki et al., 2013; Tiago and Veríssimo, 2013). The presence of Firmicutes, particularly Clostridia, was universal to all data sets, including this study (Figure 11). ML2U exhibited percent abundances of Firmicutes similar to those documented at the Cedars (Coast Range Ophiolite, California, USA) and a $\mathrm{pH} 11.2$ serpentinizing seep in the Tablelands, Newfoundland, Canada (WHC752011J CoDL 15107; Brazelton et al., 2013; Suzuki et al., 2013). Representatives of the methanogenic Methanobacterium were also common to all compared serpentinizing studies (except for the Tablelands, which did not include archaeal sequence data; Brazelton et al., 2013).

Bacteroidetes were also common (in all but two of the referenced sequence data sets), and is the most abundant taxon at ML2U (Figure 11). Betaproteobacteria were also frequently observed in serpentinizing sites, particularly the genus Hydrogenophaga, which is hypothesized to oxidize hydrogen in serpentinizing ecosystems via mechanisms not entirely understood (Suzuki et al., 2013). The sizeable biogeographical distribution of these taxa supports the hypothesis of an interconnected deep biosphere, either via meteoric water input, through the fractures and pores of the host rock, or a combination of the two. A global picture of the extent and diversity of microorganisms in the deep subsurface is beginning to emerge.

\section{CONCLUSIONS}

The microbial community at the Manleluag serpentinizing seep ecosystem demonstrates phylogenetic similarities to other serpentinizing seep ecosystems in a number of different biomes (Brazelton et al., 2010, 2013; Suzuki et al., 2013; Tiago and Veríssimo, 2013). Analysis of the outflow channel generated by the seep suggests a dynamic microbial community response to surface exposure. Surface mixing increases the redox potential of the system, thereby increasing the range of metabolic options for microorganisms in the environment. The ecotone environment enhances metabolic diversity, and increasing distance from the source pool results in decreased phylogenetic diversity. The abundance of sequences affiliated with hydrogen-oxidizing bacteria in the outflow channel also increases; this potentially indicates that hydrogen oxidation becomes favorable downstream from the source. Taxa related to heterotrophs predominate, and despite an abundance of sunlight, abundant populations of cyanobacteria were not detected. The lack of photosynthetic metabolisms likely arises from the low DIC concentrations in the serpentinizing fluids. Additionally, the abundance of organic matter (i.e., plant matter, root exudates, insects, etc...) may provide a highly favorable environment for heterotrophic dominance. Metagenomic analysis is currently underway to determine the diversity of putative metabolisms identified in this paper.

The universality of taxa such as Bacteroidetes, Clostridia, and Hydrogenophaga suggest that these microbes are ubiquitous in the subsurface environment, though the mode of dispersion is not entirely understood and requires further between- and withinsite diversity analyses. Future directions may also include the relationship between increased DIC and DOC at Manleluag in the rainy vs. the dry season, and the possible implications for calcium carbonate precipitate morphology. For example, if seasonal increases in DOC trigger banding of organic-rich layers (Figure 6), then these microstructures may serve as excellent biomarkers in serpentinite-associated carbonates, particularly in 
tropical environments that experience the same bimodal seasonality (Sánchez-Murillo et al., 2014).

\section{ACKNOWLEDGMENTS}

The authors gratefully acknowledge the tireless efforts of Gamaliel Lysander Benig Cabria, Bharathi Vallalar, Caitlin Casar, Karmina Aquino, Jeffrey Munar, and Emmanuel Codilla, without whom this study would have been impossible. The authors also thank Dr. Stefan Green, Marieta Hyde, and Ankur Nabiq for assistance with $16 \mathrm{~S}$ rRNA gene amplicon sequencing and analysis, Dr. Albert Coleman and Bo He at the University of Chicago for assistance with dissolved gas analysis, and Kristina Jarosius for assistance and training on the Hitachi S-3000N. This work would not have been possible without the generous support of NSF Grant \#s 1147334 and 1146910 to D'Arcy R. MeyerDombard and Dawn Cardace, respectively, an APS Lewis and Clark Fund for Exploration in Astrobiology Field Grant to Kristin M. Woycheese, and a C-DEBI Graduate Research Fellowship to Kristin M. Woycheese. This is EDGElab contribution \#2.

\section{SUPPLEMENTARY MATERIAL}

The Supplementary Material for this article can be found online at: http://www.frontiersin.org/journal/10.3389/fmicb. 2015.00044/abstract

\section{REFERENCES}

Abrajano, T. A., Sturchio, N. C., Bohkle, J. K., Lyon, G. L., Poreda, R. J., and Stevens, C. M. (1988). Methane-hydrogen gas seeps, Zambales ophiolite, Philippines: deep or shallow origin? Chem. Geol. 71, 211-222. doi: 10.1016/0009-2541(88)90116-7

Abrajano, T. A., Sturchio, N. C., Kennedy, B. M., Lyon, G. L., Muehlenbach, K., and Bohlke, J. K. (1990). Geochemistry of a reduced gas related to serpentinization of the Zambales Ophiolite, Philippines. Appl. Geochem. 5, 625-630. doi: 10.1016/0883-2927(90)90060-I

Amend, J. P., and Teske, A. (2005). Expanding frontiers in deep subsurface microbiology. Palaeogeogr. Palaeocl. Palaeoecol. 219, 131-155. doi: 10.1016/j.palaeo.2004.10.018

Anzai, Y., Kim, H., Park, J. Y., Wakabayashi, H., and Oyaizu, H. (2000). Phylogenetic affiliation of the pseudomonads based on $16 \mathrm{~S}$ rRNA sequence. Int. J. Syst. Evol. Micr. 50, 1563-1589. doi: 10.1099/00207713-50-4-1563

Barnes, I., O’Neil, J. R., and Trescases, J. J. (1978). Present day serpentinization in New Caledonia, Oman and Yugoslavia. Geochim. Cosmochim. Acta 42, 144-145.

Bland, C. S., Ireland, J. M., Lozano, E., Alvarez, M. E., and Primm, T. P. (2005). Mycobacterial ecology of the Rio Grande. Appl. Environ. Microbiol. 71, 5719-5727. doi: 10.1128/AEM.71.10.5719-5727.2005

Blank, J. G., Green, S. J., Blake, D., Valley, J. W., Kita, N. T., Treiman, A., et al. (2009). An alkaline spring system within the Del Puerto Ophiolite (California, USA): a Mars analog site. Planet. Space Sci. 5, 533-540. doi: 10.1016/j.pss.2008.11.018

Boldareva, E. N., Turova, T. P., Kolganova, T. V., Moskalenko, A. A., Makhneva, Z. K., and Gorlenko, V. M. (2009). Roseococcus suduntuyensis sp. nov., a new aerobic bacteriochlorophyll A-containing bacterium isolated from a lowmineralized soda lake of Eastern Siberia. Mikrobiologiia 78, 106-116. doi: 10.1134/S0026261709010123

Brazelton, W. J., Ludwig, K. A., Sogin, M. L., Andreishcheva, E. N., Kelley, D. S., Shen, C.-C., et al. (2010). Archaea and bacteria with surprising microdiversity show shifts in dominance over 1,000-year time scales in hydrothermal chimneys. Proc. Natl. Acad. Sci. U.S.A. 107, 1612-1617. doi: 10.1073/pnas.0905369107

Brazelton, W. J., Morrill, P. L., Szponar, N., and Schrenk, M. O. (2013). Bacterial communities associated with subsurface geochemical processes in continental serpentinite springs. Appl. Environ. Microb. 79, 3906-3916. doi: 10.1128/AEM.00330-13

Cabria, G. L. B., Argayosa, V. B., Lazaro, J. E. H., Argayosa, A. M., and Arcilla, C. A. (2014). Draft genome sequence of haloalkaliphilic Exiguobacterium sp.
Strain AB2 from Manleluag Ophiolite Spring, Philippines. Genome Announc. 2, e00840-e00814. doi: 10.1128/genomeA.00840-14

Caporaso, J. G., Bittinger, K., Bushman, F. D., DeSantis, T. Z., Andersen, G. L., and Knight, R. (2010b). PyNAST: a flexible tool for aligning sequences to a template alignment. Bioinformatics 26, 266-267. doi: 10.1093/bioinformatics/btp636

Caporaso, J. G., Kuczynski, J., Stombaugh, J., Bittinger, K., Bushman, F. D., Costello, E. K., et al. (2010a). QIIME allows analysis of high-throughput community sequencing data. Nat. Methods 7, 335-336. doi: 10.1038/nmeth.f.303

Cardace, D., and Hoehler, T. (2009). Serpentinizing fluids craft microbial habitat. Northeast. Nat. 16, 272-284. doi: 10.1656/045.016.0520

Cardace, D., Hoehler, T., McCollom, T., Schrnk, M., Carnevale, D., Kubo, M., et al. (2013). Establishment of the Coast Range ophiolite microbial observatory (CROMO): drilling objectives and preliminary outcomes. Sci. Dril. 1, 45-55. doi: 10.5194/sd-16-45-2013

Cardace, D., Meyer-Dombard, D. R., Woycheese, K. M., and Arcilla, C. A. (2015). Feasible metabolisms in high $\mathrm{pH}$ springs of the Philippines. Front. Microbiol. 6:10. doi: 10.3389/fmicb.2015.00010

DeSantis, T. Z., Hugenholtz, P., Larsen, N., Rojas, M., Brodie, E. L., Keller, K., et al. (2006). Greengenes, a chimera-checked 16S rRNA gene database and workbench compatible with ARB. Appl. Environ. Microb. 72, 5069-5072. doi: 10.1128/AEM.03006-05

Dong, L., Ming, H., and Yin, Y. (2014). Roseomonas alkaliterrae sp. nov., isolated from an alkali geothermal soil sample in Tenchong, Yunnan, southwest China. Antonie Van Leeuwenhoek 105, 899-905. doi: 10.1007/s10482-0140144-1

Edgar, R. C. (2010). Search and clustering orders of magnitude faster than BLAST. Bioinformatics 26, 2460-2461. doi: 10.1093/bioinformatics/btq461

Etiope, G., Schoell, M., and Hosgörmez, H. (2011). Abiotic methane flux from the Chimaera seep and Tekirova ophiolites (Turkey): understanding gas exhalation from low temperature serpentinization and implications for Mars. Earth Planet. Sci. Lett. 310, 96-104. doi: 10.1016/j.epsl.2011.08.001

Fredrickson, J. K., Balkwill, D. L., Romine, M. F., and Shi, T. (1999). Ecology, physiology, and phylogeny of deep subsurface Sphingomonas sp. J. Ind. Microbiol. Biot. 23, 273-283. doi: 10.1038/sj.jim.2900741

Hawkins, J. W., and Evans, C. A. (1983). "Geology of the Zambales Range, Luzon, Philippine Islands: Ophiolite derived from an Island Arc-Back Arc Basin Pair," in The Tectonic and Geologic Evolution of Southeast Asian Seas and Islands: Part 2, ed D. E. Hayes (Washington, DC: American Geophysical Union), 95-124. doi: 10.1029/GM027p0095

Heulin, T., Barakat, M., Christen, R., Lesourd, M., Sutra, L., De Luca, G., et al. (2003). Ramlibacter tataouinensis gen. nov. sp. nov., and Ramlibacter henchirensis sp. nov., cyst-producing bacteria isolated from subdesert soil in Tunisia. Int. J. Syst. Evol. Micr. 53, 589-594. doi: 10.1099/ijs.0.02482-0

Jungbluth, S. P., Lin, H.-T., Cowen, J. P., Glazer, B. T., and Rappe, M. S. (2014). Phylogenetic diversity of microorganisms in subseafloor crustal fluids from Holes $1025 \mathrm{C}$ and 1026B along the Juan de Fuca Ridge flank. Front. Microbiol. 5:119. doi: 10.3389/fmicb.2014.00119

Kallmeyer, J., Pockalny, R., Adhikari, R. R., Smith, D. C., and D'Hondt, S. (2012). Global distribution of microbial abundance and biomass in subseafloor sediment. Proc. Nat. Acad. Sci. U.S.A. 109, 16213-16216. doi: 10.1073/pnas.1203849109

Kelly, D. P., and Wood, A. P. (2000). Reclassification of some species of Thiobacillus to the newly designated genera Acidothiobacillus gen. nov. Halothiobacillus gen. nov. and Thermithiobacillus gen. nov. Int. J. Syst. Evol. Micr. 50, 511-516. doi: 10.1099/00207713-50-2-511

Kolari, M., Nuutinen, J., Rainey, F. A., and Salkinoja-Salonen, M. S. (2003). Colored moderately thermophilic bacteria in paper-machine biofilms. J. Ind. Microbiol. Biotechnol. 30, 223-238. doi: 10.1007/s10295-003-0047-z

Lautenschlager, K., Hwang, C., Liu, W. T., Boon, N., Koster, O., Vrouwenvelder, H., et al. (2014). A microbiology-based multi-parametric approach towards assessing biological stability in drinking water distribution networks. Water Res. 47, 3015-3025. doi: 10.1016/j.watres.2013.03.002

Lozupone, C., and Knight, R. (2005). UniFrac: a new phylogenetic method for comparing microbial communities. Appl. Environ. Microbiol. 71, 8228-8235. doi: 10.1128/AEM.71.12.8228-8235.2005

Makarova, K. S., Aravind, L., Wolf, Y. I., Tatusov, R. L., Minton, K. W., Koonin, E. V., et al. (2001). Genome of the extremely radiation-resistant bacterium Deinococcus radiodurans viewed from the perspective of comparative genomics. Microbiol. Mol. Biol. Rev. 65, 44-79. doi: 10.1128/MMBR.65.1.44-79.2001 
Marlow, J. J., LaRowe, D. E., Ehlmann, B. L., Amend, J. P., and Orphan, V. J. (2014). The potential for biologically catalyzed anaerobic methane oxidation on ancient Mars. Astrobiology 14, 292-307. doi: 10.1089/ast.2013.1078

McDonald, D., Price, M. N., Goodrich, J., Nawrocki, E. P., DeSantis, T. Z., Probst, A., et al. (2012). An improved Greengenes taxonomy with explicit ranks for ecological and evolutionary analyses of bacteria and archaea. ISME J. 6, 610-618. doi: 10.1038/ismej.2011.139

Meyer-Dombard, D. R., Woycheese, K. M., Yargıçoğlu, E. N., Cardace, D., Shock, E. L., Güleçal-Pektas, Y., et al. (2015). High pH microbial ecosystems in a newly discovered, ephemeral, serpentinizing fluid seep at Yanartaş (Chimera), Turkey. Front. Microbiol. 5:723. doi: 10.3389/fmicb.2014.00723

Morse, J. W., and Arvidson, R. S. (2002). The dissolution kinetics of major sedimentary carbonate minerals. Ear. Sci. Rev. 58, 51-84. doi: 10.1016/S00128252(01)00083-6

Moser, D. P., Gihring, T. M., Brockman, F. J., Fredrickson, J. K., Balkwill, D. L., Dollhopf, M. E., et al. (2005). Desulfotomaculum and Methanobacterium spp. dominate a 4- to 5-kilometer-deep fault. Appl. Environ. Microbiol. 71, 8773-8783. doi: 10.1128/AEM.71.12.8773-8783.2005

Nealson, K. H., Inagaki, F., and Takai, K. (2005). Hydrogen-driven subsurface lithoautotrophic microbial ecosystems (SLiMEs): do they exist and why should we care? TRENDS Microbiol. 13, 405-410. doi: 10.1016/j.tim.2005.07.010

Pikuta, E. V., Hoover, R. B., Bej, A. K., Marsic, D., Whitman, W. B., Cleland, D., et al. (2003). Desulfonatronum thiodismutans sp. nov., a novel alkaliphilic, sulfate-reducing bacterium capable of lithoautotrophic growth. Int. J. Syst. Evol. Microbiol. 53, 1327-1332. doi: 10.1099/ijs.0.02598-0

Price, M. N., Dehal, P. S., and Arkin, A. P. (2010). FastTree 2 - approximately maximum-likelihood trees for large alignments. PLoS ONE 5:e9490. doi: 10.1371/journal.pone.0009490

Russell, M. J. (2003). Geochemistry: the importance of being alkaline. Science 302, 580-581. doi: 10.1126/science.1091765

Sánchez-Murillo, R., Gazel, E., Schwarzenbach, E., Crespo-Medina, M., Schrenk, M. O., Boll, J., et al. (2014). Geochemical evidence for active tropical serpentinization in the Santa Elena Ophiolite, Costa Rica: an analog of a humid early Earth? Geochem. Geophys. Geosyst. 15, 1783-1800. doi: 10.1002/2013GC 005213

Schrenk, M. O., Brazelton, W. J., and Lang, S. Q. (2013). Serpentinization, carbon, and deep life. Rev. Mineral. Geochem. 75, 575-606. doi: 10.2138/rmg.2013.75.18

Sorokin, D. Y., Tourova, T. P., Mussmann, M., and Muyzer, G. (2008). Dethiobacter alkaliphilus gen. nov. sp. nov., and Desulfurivibrio alkaliphilus gen. nov. sp. nov.: two novel representatives of reductive sulfur cycle from soda lakes. Extremophiles 12, 431-439. doi: 10.1007/s00792-008-0148-8

Spang, A., Poehlein, A., Offre, P., Zumbragel, S., Haider, S., Rychlik, N., et al. (2012). The genome of the ammonia-oxidizing Candidatus Nitrososphaera gargensis: insights into metabolic versatility and environmental adaptations. Environ. Microbiol. 14, 3122-3145. doi: 10.1111/j.1462-2920.2012.02893.x

Suzuki, S., Ishii, S., Wu, A., Cheung, A., Tenney, A., Wanger, G., et al. (2013). Microbial diversity in The Cedars, an ultrabasic, ultrareducing, and low salinity serpentinizing ecosystem. Proc. Natl. Acad. Sci. U.S.A. 110, 15336-15341. doi: 10.1073/pnas.1302426110

Szponar, N., Brazelton, W. J., Schrenk, M. O., Bower, D. M., Steele, A., and Morrill, P. L. (2013). Geochemistry of a continental site of serpentinization, the Tablelands Ophiolite, Gros Morne National Park: a Mars analogue. Icarus 22, 286-296. doi: 10.1016/j.icarus.2012.07.004

Takai, K., Moser, D. P., Onstott, T. C., Spoelstra, N., Pfiffner, S. M., Dohnalkova, A., et al. (2001). Alkaliphilus transvaalensis gen. nov., sp. nov., an extremely alka- liphilic bacterium isolated from a deep South African gold mine. Int. J. Syst. Evol. Microbiol. 51, 1245-1256. doi: 10.1099/00207713-51-4-1245

Tiago, I., and Veríssimo, A. (2013). Microbial and functional diversity of a subterrestrial high $\mathrm{pH}$ groundwater associated to serpentinization. Environ. Microbiol. 15, 1687-1706. doi: 10.1111/1462-2920.12034

Tindall, B., Sikorski, J., Lucas, S., Goltsman, E., Copeland, A., Glavina Del Rio, T., et al. (2010). Complete genome sequence of Meiothermus ruber type strain $\left(21^{\mathrm{T}}\right)$. Stand. Genomic Sci. 3, 26-36. doi: 10.4056/sigs.1032748

Vazquez-Baeza, Y., Pirrung, M., Gonzalez, A., and Knight, R. (2013). Emperor: a tool for visualizing high-throughput microbial community data. Gigascience 2:16. doi: 10.1186/2047-217X-2-16

Vishnivetskaya, T. A., Kathariou, S., and Tiedje, J. M. (2009). The Exiguobacterium genus: biodiversity and biogeography. Extremophiles 1, 541-555. doi: 10.1007/s00792-009-0243-5

Walters, W. A., Caporaso, J. G., Lauber, C. L., Berg-Lyons, D., Fierer, N., and Knight, R. (2011). PrimerProspector: de novo design and taxonomic analysis of barcoded polymerase chain reaction primers. Bioinformatics 27, 1159-1161. doi: 10.1093/bioinformatics/btr087

Wang, Q., Garrity, G. M., Tiedje, J. M., and Cole, J. R. (2007). Naïve Bayesian classifier for rapid assignment of rRNA sequences into the new bacterial taxonomy. Appl. Environ. Microb. 73, 5261-5267. doi: 10.1128/AEM.00062-07

Werner, J. J., Koren, O., Hugenholtz, P., DeSantis, T. Z., Walters, W. A., Caporaso, J. G., et al. (2012). Impact of training sets on classification of high-throughput bacterial 16S rRNA gene surveys. ISME J. 6, 94-103. doi: 10.1038/ismej.2011.82

Whitman, W. B., Coleman, D. C., and Wiebe, W. J. (1998). Prokaryotes: the unseen majority. Proc. Natl. Acad. Sci. U.S.A. 95, 6578-6583. doi: 10.1073/pnas.95.12.6578

Yoon, J. H., Lee, K. C., Weiss, N., Kho, Y. H., Kang, K. H., and Park, Y. H. (2001). Sporosarcina aquimarina sp. nov., a bacterium isolated from seawater in Korea, and transfer of Bacillus globisporus (Larkin and Stokes 1967), Bacillus psychrophilus (Nakamura 1984) and Bacillus pasteurii (Chester 1898) to the genus Sporosarcina as Sporosarcina globispora comb. nov., Sporosarcina psychrophila comb. nov. and Sporosarcina pasteurii comb. nov., and emended description of the genus Sporosarcina. Int. J. Syst. Evol. Microbiol. 5, 1079-1086. doi: 10.1099/00207713-51-3-1079

Conflict of Interest Statement: The authors declare that the research was conducted in the absence of any commercial or financial relationships that could be construed as a potential conflict of interest.

Received: 01 September 2014; paper pending published: 04 November 2014; accepted: 13 January 2015; published online: 19 February 2015.

Citation: Woycheese KM, Meyer-Dombard DR, Cardace D, Argayosa AM and Arcilla CA (2015) Out of the dark: transitional subsurface-to-surface microbial diversity in a terrestrial serpentinizing seep (Manleluag, Pangasinan, the Philippines). Front. Microbiol. 6:44. doi: 10.3389/fmicb.2015.00044

This article was submitted to Extreme Microbiology, a section of the journal Frontiers in Microbiology.

Copyright (C) 2015 Woycheese, Meyer-Dombard, Cardace, Argayosa and Arcilla. This is an open-access article distributed under the terms of the Creative Commons Attribution License (CC BY). The use, distribution or reproduction in other forums is permitted, provided the original author(s) or licensor are credited and that the original publication in this journal is cited, in accordance with accepted academic practice. No use, distribution or reproduction is permitted which does not comply with these terms. 